\title{
Influence of as-built surface and heat treatment on the fatigue resistance of Additively Layer Manufacturing (ALM) AISi10Mg alloy.
}

\author{
Julius Noel Domfang Ngnekou ${ }^{1,2^{*}}$, Julien Nicolai ${ }^{1}$, Yves $\operatorname{Nadot}^{1}$, Gilbert Henaff ${ }^{1}$, Lionel Ridosz ${ }^{2}$, \\ ${ }^{1}$ Institut Pprime UPR CNRS 3346, Department of Physique and Mechanics of Materials, ENSMA-Université de Poitiers, 1 avenue \\ Clément Ader, Téléport 2, 86960 Chasseneuil-Futuroscope, France \\ ${ }^{2}$ Zodiac Aerospace, 61 rue Pierre Curie, 78370 Plaisir, France
}

\begin{abstract}
This work concerns the fatigue resistance of a AlSi10Mg material produced by additive manufacturing, and more precisely the competition between as built manufacturing surface and as-machined surface on the fatigue resistance. Samples were built by a powder-bed process with an EOS-M280 machine using standard in two configurations $\left(0^{\circ}\right.$ and $\left.90^{\circ}\right)$ in order to evaluate the impact of building direction on fatigue life. The impact of as-built surface on fatigue behavior is quantified for each specimen configuration. A T6 heat treatment is performed on samples in order to evaluate the impact of microstructure on fatigue behavior. For each configurations, the S-N curves is determined in as-built and T6 materials with a load ratio $\mathrm{R}=-1$. The fracture surfaces are carefully analyzed in order to determine the critical defect size for each sample. A Kitagawa type diagram representing the fatigue limit as a function of the defect size is derived from these measurements. All the results were compared to those obtained in asmachined samples.
\end{abstract}

\section{Introduction}

Additive Layer Manufacturing (ALM) is a breakthrough process compared to conventional processes such as casting, in particular to produce parts with a complex shape. In the aeronautic context, the introduction of such an innovative process implies a qualification process in which the understanding of the fatigue resistance is crucial [1-3]. Thus, the characterization of the microstructure inherited from the process is required in order to access the impact of a given microstructure on the fatigue behaviour. According to Domfang et al [4], the microstructure in the bulk of the non-heat treated ALM AlSi10Mg material can be described using five parameters: (i) defect population, (ii) melt-pools, (iii) dendritic structure, (iv) precipitation structure and (v) grains. It has been observed that melt-pools, dendritic structure and grains are strongly anisotropic in shape depending on the building direction. In addition the melt-pools and dendrites disappear after a T6 heat treatment [4]. On the other hand, the surfaces of near net-shape pieces are characterized by a high roughness that could impact the fatigue behavior. Since most of the ALM parts are partially machined, the aim of this study is to compare the fatigue behavior of as-machined samples to samples with a near net shape cross section also called as-built samples.

\section{Samples fabrication}

Specimens were fabricated by ALM method using a prealloyed powder with an average particle size of $30 \mu \mathrm{m}$. All specimens were constructed using a EOS INT-M290 machine with standard parameters. The layering is performed by means of a scraper. Two families of specimen are considered in this study and denominated P2 and P3. P2 specimens were machined from cylinders bars while P3 were manufactured with a near net-shape cross section. All specimens were constructed on a platform placed at $200^{\circ} \mathrm{C}$. The materials thus manufactured were all subjected to a soft post-blast treatment to clean the surface. This cleaning was carried out using micro glass oxide marbles with a size of the order of 100 to 200 microns. These marbles were projected from about $10 \mathrm{~cm}$ to the specimen with a jet pressure of 4 bars. Before cutting specimen from the platform, a recommended stress relaxation treatment was performed during 2 hours at $210^{\circ} \mathrm{C}$. P2 and P3 specimens were built along two directions, namely $\mathrm{XY}$ and $\mathrm{Z}$ as defined in Figure 1-a. P2 fatigue test specimens were machined (MA) from the bars in order to overcome the manufacturing gross surface integrity effects, namely the surface roughness and the presence of a population of defects in the subsurface due to edge lasing $[5,6]$. One bar corresponds to one specimen. No polishing was applied on the sample surfaces. On the other hand, for P3 fatigue specimen tests only threads were machined while 
the gauge length was left in the as-built condition. In the specific case of P3 XY specimens, the production supports were removed by means of grinding wheel. Some specimens have subsequently been subjected to a T6 heat treatment with conditions listed in Table 2, leading to a denomination of each individual fatigue specimen given in Table 3. This denomination used in this paper depends on the production number, the orientation and the application or not of a T6 treatment.
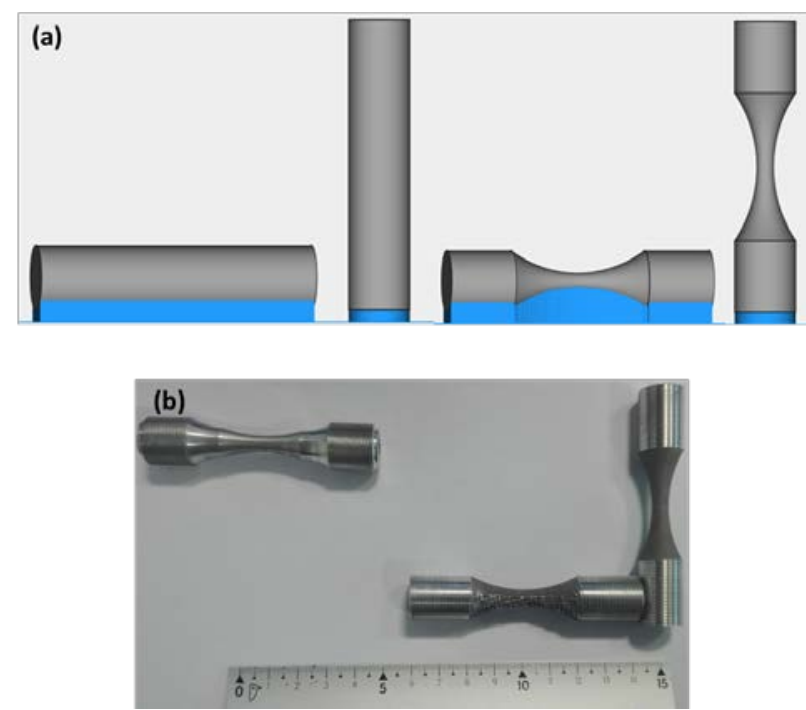

Figure 1:(a) manufactured parts from which samples where removed, (b) left: machined sample, right: near-net shape samples

Table 1: description of the T6 heat-treatment

\begin{tabular}{|l|c|c|c|}
\hline Steps & $\begin{array}{c}\text { Temperature } \\
\left({ }^{\circ} \mathrm{C}\right)\end{array}$ & Duration (h) & Environment \\
\hline $\begin{array}{l}\text { Solid } \\
\text { solutioning }\end{array}$ & 540 & 8 & Air \\
\hline Quenching & 20 & & Water \\
\hline Tempering 1 & 20 & 24 & Air \\
\hline Tempering 2 & 160 & 10 & Air \\
\hline
\end{tabular}

Table 2: sample designation

\begin{tabular}{|c|c|c|c|c|}
\hline Production & Type & T6 & $\begin{array}{c}\text { Machine } \\
\text { /As-Built }\end{array}$ & Designation \\
\hline \multirow{4}{*}{ P2 } & XY & $\begin{array}{c}\text { No } \\
\text { Yes }\end{array}$ & $\begin{array}{c}\text { Machined } \\
\text { (MA) }\end{array}$ & $\begin{array}{c}\text { P2-XY-MA } \\
\text { P2-XY-MA-T6 }\end{array}$ \\
\cline { 2 - 5 } & Z & $\begin{array}{c}\text { No } \\
\text { Yes }\end{array}$ & $\begin{array}{c}\text { Machined } \\
\text { (MA) }\end{array}$ & $\begin{array}{c}\text { P2-Z-MA } \\
\text { P2-Z-MA-T6 }\end{array}$ \\
\hline \multirow{4}{*}{ P3 } & XY & $\begin{array}{c}\text { No } \\
\text { Yes }\end{array}$ & $\begin{array}{c}\text { As-Built } \\
\text { (AB) }\end{array}$ & $\begin{array}{c}\text { P3-XY-AB } \\
\text { P3-XY-AB-T6 }\end{array}$ \\
\cline { 2 - 5 } & $Z$ & $\begin{array}{c}\text { No } \\
\text { Yes }\end{array}$ & $\begin{array}{c}\text { As-Built } \\
\text { (AB) }\end{array}$ & $\begin{array}{c}\text { P3-Z-AB } \\
\text { P3-Z-AB-T6 }\end{array}$ \\
\hline
\end{tabular}

\section{Experiments}

An Energy Dispersive Spectrometry (EDS) analysis was carried out to quantify the chemical elements present in the alloy. The results reported in Table 3 show that the composition determined is in accordance with the standard composition. However, the non-detection of some elements such as iron means that the EDS technique is not able to quantify this particular component, especially when it is present in a small proportion and homogeneously distributed in the volume.

The fatigue limit were defined at one million cycles. A step by step method was used, as it is the only way to evaluate the fatigue limit in presence of natural defects. It is however assumed that no significant loading history effect is introduced by the loading steps applied prior to failure, as shown by Roy et al [7] in the case of a A356 cast Al-alloy. In order to plot a Kitagawa-type diagram, the fatigue limit is determined for each specimen after failure according to the following method:

- When the specimen fails during the first step, a Basquin equation is used to calculate the fatigue limit.

$$
\sigma_{D-1}^{t e}=A \times N_{f}^{\alpha}
$$

- When the specimen fails after one or several loading steps, the fatigue limit is determined by a linear interpolation according to the following equation:

$$
\sigma_{D-1}^{t e}=\frac{N_{f}}{10^{6}} \times\left(\sigma_{n}-\sigma_{n-1}\right)+\sigma_{n-1}
$$

Table 3: chemical composition of AlSilOMg

\begin{tabular}{|l|l|l|c|}
\hline & Al & $\mathrm{Si}$ & $\mathrm{Mg}$ \\
\hline $\begin{array}{l}\text { DIN EN } \\
1706: 2010\end{array}$ & Bal. & $9-11$ & $0.2-0.45$ \\
\hline $\begin{array}{l}\text { W\% EDX } \\
\text { measure }\end{array}$ & Bal. & 9.55 & 0.4 \\
\hline
\end{tabular}


(a)

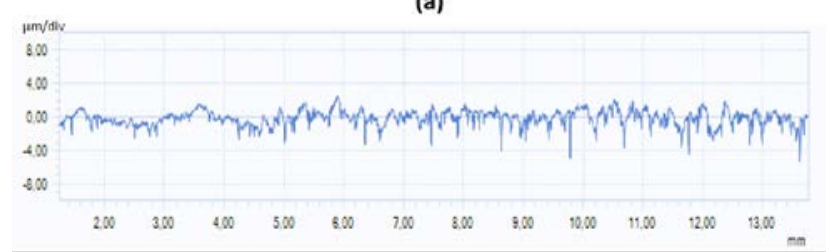

(b)

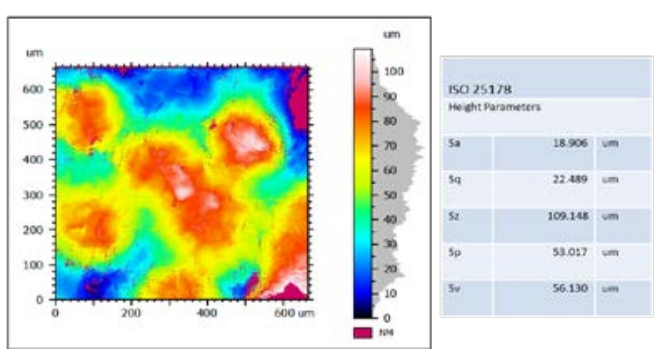

Figure 2: surface roughness characterization (a) machined samples (b) near-net shape sample using interferometric profilometer

\section{Results and discussion}

In Figure 3 the fatigue S-N curves of P2 and P3 machined or as-built, with or without heat treatment. For machined samples, two directions are study: XY and Z while for as-built samples the oblique samples are furthermore presented.. The black symbols correspond to the samples tested without T6 and open symbols correspond to heat treated samples. One point corresponds to one experimental failure of a given sample.. Even though the microstructure is strongly anisotropic [8-10], no difference in fatigue strength is noticed between samples machined along $\mathrm{XY}$ and $\mathrm{Z}$ directions. However they is a small impact of building strategy for as-built samples. However, in the case of asbuilt surfaces, the scatter in data exhibits only a subtle dependence on the building direction. Those differences can be related to the surface roughness. Figure 3 clearly shows that the as-built samples are less resistant to fatigue than the machined ones, even after a peak hardening $\mathrm{T} 6$ heat treatment. The fracture surface

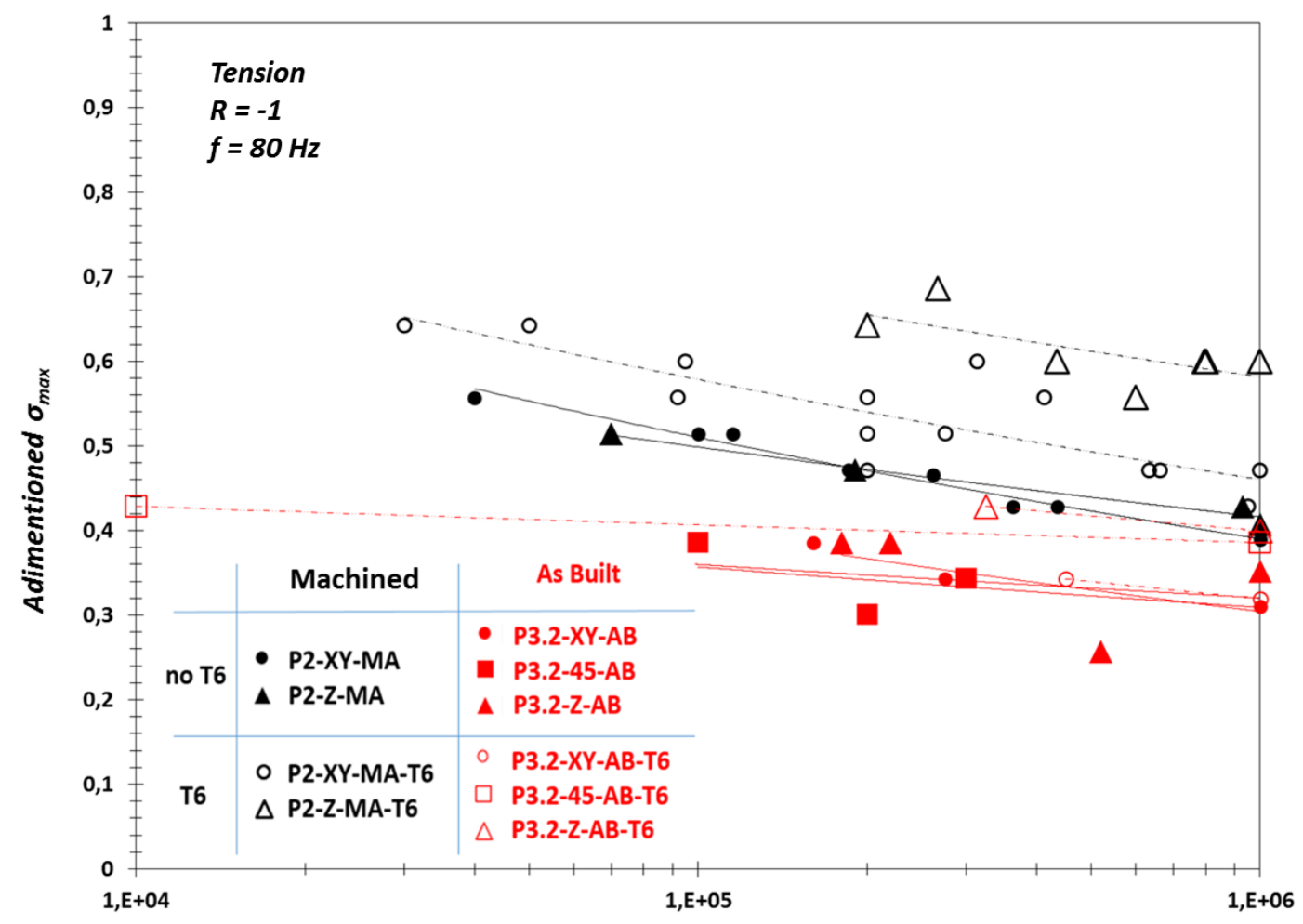

Number of cycles to failure

Figure 3: effect of building direction, defect and T6 heat-treatment on fatigue life. 

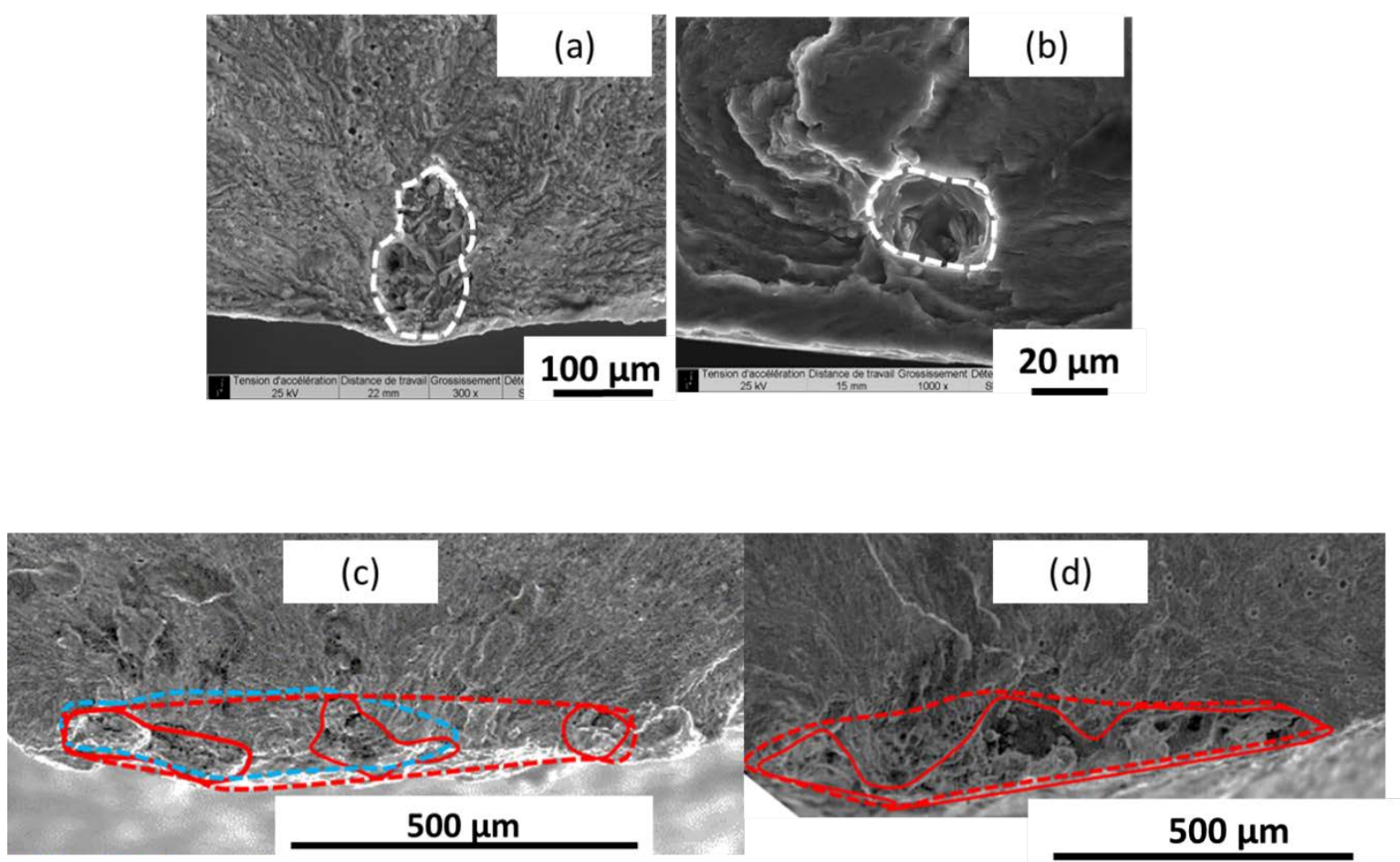

Figure 4: SEI images of initiation sites on fracture surfaces (a,b) P2-MA (c, d) P3-AB

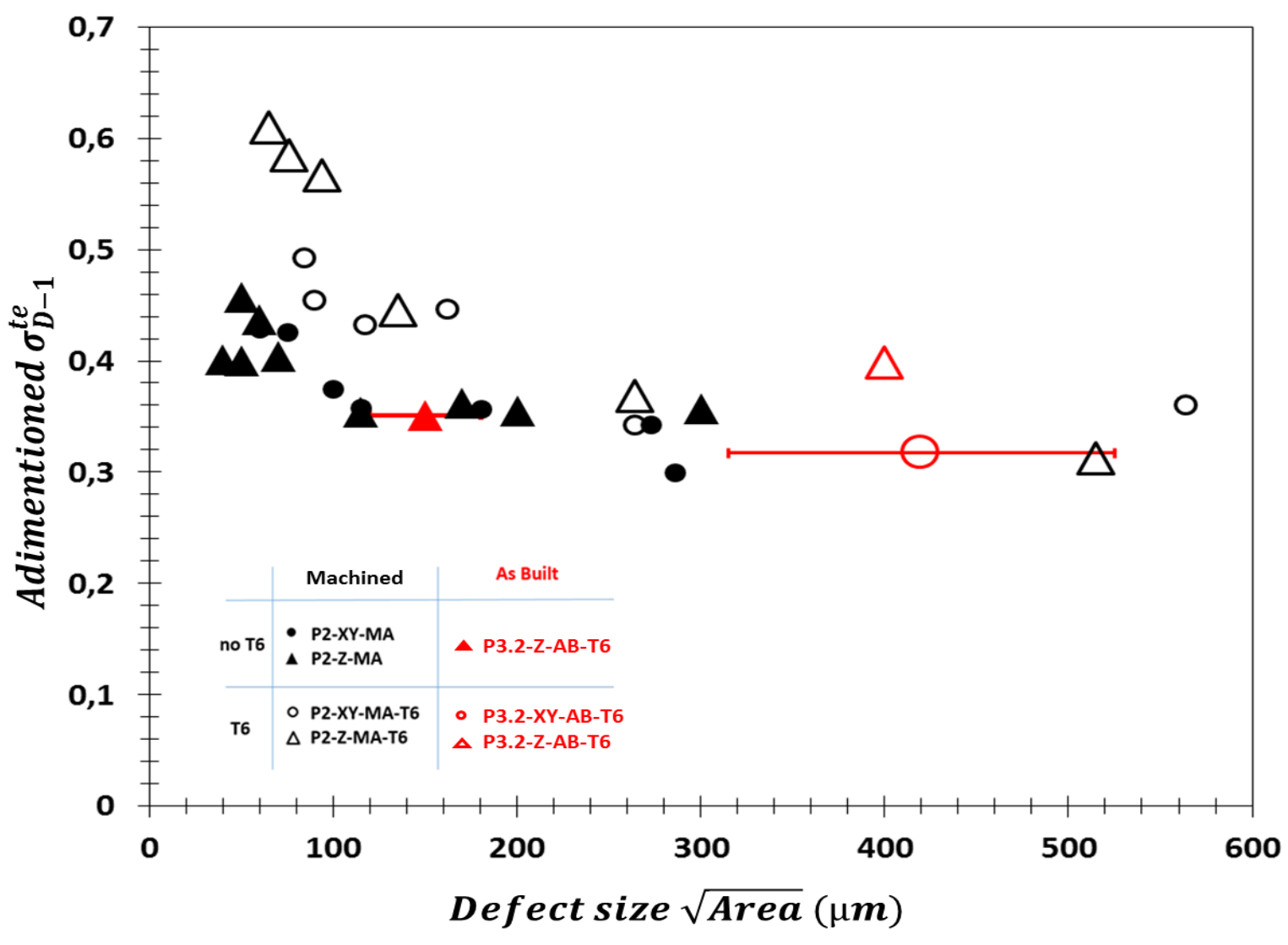

Figure 5: Kitagawa-type diagram showing the impact of heat treatment, specimen building orientation and surface roughness.

examination in Figure 4 furthermore suggests that the P3 production contains larger defects than $\mathrm{P} 2$. As it can be observed in Figure 2, that as-built samples (P3) are more rough than machined ones $(\mathrm{P} 2)$ the fatigue drop is due at least to roughness and defect size. For each productions P2 and P3 specimens containing similar defects, an 
improvement in fatigue resistance is noticed after T6 heat treatment. Figure 5 exhibit the impact of defect size on the fatigue limit through the Kitagawa type diagram. In order to plot the Kitagawa diagram, the defect size was measure on fractures surfaces using Murakami parameter [11]. In this way, Figure 5 consolidates the SN curves interpretations in terms of impact of building direction and heat treatment. However it clear that the impact of HT seems to dwindle in presence of big defects. Same approach was carry out for surfaces as-built specimen. So, fracture surfaces of as-built failed samples was analysed and the defect size was quantified with and without T6 heat treatment. Fatigue limit was calculated and associated to a corresponding defect size. Results as compared to machined Kitagawa diagram on Figure 5. Even in the presence of a degraded surface and regardless the heat treatment, the results of the as-built specimens coincide with those of the machined specimens. Meaning that the defect size seems to be the first order parameter that controlled the fatigue limit.

\section{Conclusion}

This study addresses the fatigue behaviour of AlSi10Mg alloy elaborated by selective laser melting. The impact of as-built surface have been quantified and compared to machined surface. On the basis of the Kitagawa diagram established, it has been observed that the defect size is the first order parameter that controls the fatigue limit. For both machined and as-built samples, the T6 heat treatment improves the fatigue limit and reveal a slight building orientation effect.

\section{Acknowledgement}

The authors gratefully acknowledges funding provided by Zodiac Aerospace and French National Research and Technology Association (ANRT). This work has been partially supported by «Nouvelle Aquitaine » Region and by European Structural and Investment Funds (ERDF reference: P-2016-BAFE-94/95). Finally the authors would like to thanks Thierry Rouge-Carassat for his comment on a present manuscript.

\section{References}

1. S. Romano, A. Brandão, J. Gumpinger, M. Gschweitl, S.B. a, Mater. Des., 131, 32-48, (2017).

2. L. Portolés, O. Jordá, L. Jordá, A. Uriondo, M. Esperon-Miguez, S. Perinpanayagam, J. Manuf. Syst., 41, 65-75, (2016).

3. J. Mardaras, P. Emile, A. Santgerma, Procedia Struct. Integr., 7, 109-115, (2017).
4. J.N.D. Ngnekou, G. Henaff, Y. Nadot, J. Nicolai, L. Ridosz, Procedia Eng., 213, 79-88, (2018).

5. K. V. Yang, P. Rometsch, T. Jarvis, J. Rao, S. Cao, C. Davies, X. Wu, Mater. Sci. Eng. A, 712, 166-174, (2018).

6. J. Damon, S. Dietrich, F. Vollert, J. Gibmeier, V. Schulze, Addit. Manuf., 20, 77-89, (2018).

7. M. Iben Houria, Y. Nadot, R. Fathallah, M. Roy, D.M. Maijer, Int. J. Fatigue, 80, 90-102, (2015).

8. J.N. Domfang Ngnekou, Y. Nadot, G. Henaff, J. Nicolai, L. Ridosz, Procedia Struct. Integr., 7, 75-83, (2017).

9. N. Takata, H. Kodaira, K. Sekizawa, A. Suzuki, M. Kobashi, Mater. Sci. Eng. A, A 704, 218228, (2017).

10. W. Li, S. Li, J. Liu, A. Zhang, Y. Zhou, Q. song Wei, C. Yan, Y. Shi, Mater. Sci. Eng., A 663, 116-125, (2016).

11. Y. Murakami, M. Endo, Int. J. Fatigue, 16, 163182, (1994). 